\title{
Fulminant hepatic failure during pregnancy.
}

1. FCPS

Associate Professor Medicine

Nishtar Medical University, Multan.

2. FRCP

Professor / HOD Medicine Nishtar Medical College, Multan.

Multan Medical and Dental College, Multan.

3. Final Year MBBS Student Nishtar Medical University, Multan.

Correspondence Address:

Dr. Zahra Nazish

Department of Medicine

Nishtar Medical University, Multan.

zahranazish@gmail.com

Article received on:

03/12/2020

Accepted for publication:

$15 / 03 / 2021$
Zahra Nazish$^{1}$, Muhammad Inayatullah², Fatima Tu Zahra ${ }^{3}$

ABSTRACT... Objective: To observe clinical characteristics, etiology and maternal outcome in fulminant hepatic failure during pregnancy. Study Design: Observational Prospective Study. Setting: Department of Medicine, Nishtar Hospital Multan. Period: January 2013 to December 2017. Material \& Methods: Twenty nine consecutive patients with fulminant hepatic failure during pregnancy were included in the study. Results: Mean age of patients was $27.06 \pm 6.92$ years. $65.51 \%$ patients were from urban areas. Mean duration of gestation was $24.80 \pm 6.03$ weeks. Jaundice and altered consciousness were observed in $100 \%$ cases, pallor in $79.31 \%$, hepatomegaly in $20.68 \%$, flapping tremors in $10.34 \%$, ascites in $10.34 \%$ and splenomegaly in $6.89 \%$ cases. Complications observed were cerebral edema in $44.82 \%$, renal failure in $24.13 \%$, bleeding in $20.68 \%$ and hypoglycemia in $3.44 \%$. Most common cause was acute hepatitis $\mathrm{E}$ $(75.86 \%)$ followed by hepatitis B $(13.79 \%)$ and hepatitis A $(3.44 \%)$. No cause was found in $6.89 \%$ cases. Overall maternal mortality was $37.93 \%$ and fetal mortality was $72.41 \%$. In $17.24 \%$ cases pregnancy was terminated therapeutically, $44.82 \%$ cases had spontaneous expulsion and in $37.93 \%$ cases pregnancy continued. Maternal mortality was highest $(45.45 \%)$ in patients who remained pregnant as compared to $20 \%$ when pregnancy was terminated therapeutically. Conclusion: Jaundice and altered conscious level is the most common clinical presentation. Hepatitis $\mathrm{E}$ is the most common cause of FHF in pregnancy. Maternal mortality in FHF during pregnancy is very high.

Key words: $\quad$ Fulminant Hepatic Failure, Maternal Outcome, Pregnancy.

Article Citation: Nazish Z, Inayatullah M, Fatima Tu Zahra. Fulminant hepatic failure during pregnancy. Professional Med J 2021; 28(10):1501-1507. https://doi.org/10.29309/TPMJ/2021.28.10.6247

\section{INTRODUCTION}

Fulminant hepatic failure (FHF) in pregnancy, although uncommon, is a serious condition associated with high maternal and fetal mortality.

There are many causes of FHF but viral hepatitis is most common in our country. Viral hepatitis is caused by six types of virus: hepatitis $A, B, C, D$, $E$ and $G$. Hepatitis $E$ in pregnancy is associated with severe liver dysfunction and progression to acute liver failure. ${ }^{1} \mathrm{FHF}$ presents with altered mental status, derangement of liver function tests and coagulopathy. FHF has $40 \%$ mortality and liver transplantation is the only treatment option. ${ }^{2}$ Facility of liver transplantation is not available in our set up. Management is supportive and we wait for liver to regenerate.

In pregnant women there is excessive metabolic burden on the liver which makes it difficult to recover. Because of the interaction between pregnancy and hepatitis, there is severe immunologic response and a large number of liver cells will undergo necrosis rapidly. Therefore acute hepatitis can aggravate very quickly and complications are more likely to develop. ${ }^{3,4}$ Maternal mortality is reported to be high in many parts of the world in $\mathrm{FHF}^{5}$

Rationale of this study was to enhance our knowledge about the clinical characteristics, etiology, and maternal outcome in FHF during pregnancy so as to identify appropriate measures to reduce morbidity and mortality.

\section{OBJECTIVE}

To observe clinical characteristics, etiology and maternal outcome in fulminant hepatic failure 
during pregnancy.

\section{MATERIAL \& METHODS}

This study was conducted in the department of Medicine Nishtar Hospital Multan from January 2013 to December 2017 after permission from Head of department. Consecutive 29 patients who presented with fulminant hepatic failure during pregnancy were included in the study. Patients with underlying chronic liver disease were excluded. Patients were evaluated on the basis of history, examination and investigations including liver function tests, serum albumin, prothrombin time, renal parameters, viral serology ( IgM anti HAV, HBsAg, IgM anti HBc, anti HCV, IgM anti HEV), serum uric acid and abdominal ultrasound. CT scan head was done in patients with signs of raised intracranial pressure. Patients were classified into three groups based on outcome of pregnancy (therapeutic termination of pregnancy, spontaneous expulsion of fetus, pregnancy continued).

Data was analysed using Statistical Package for Social Sciences (SPSS) version 20. Descriptive analysis was applied to calculate frequency and percentage for qualitative variables. Mean and standard deviation was calculated for quantitative variables.

\section{RESULTS}

Mean age of our patients was 27.06 \pm 6.9 (18 45) years. Nineteen (65.51\%) patients were from urban areas and 10 (34.48\%) from rural areas. Twenty six (89.65\%) patients were housewives. Mean duration of gestation at the time of presentation was $24.80 \pm 6.03$ (8-32) weeks.

Twenty nine (100\%) patients presented with altered consciousness, 26(89.65\%) with yellowness of eyes, $10(34.48 \%)$ with fever, 06(20.68\%) with vomiting, 03(10.34\%) with pain in right hypochondrium.

The most common signs were jaundice observed in $29(100 \%)$ cases and pallor observed in $23(79.31 \%)$ cases. Mean duration of jaundice at the time of presentation was 9.2 \pm 16.6 (1-90 days) days and encephalopathy was $1.92 \pm 1.1$ (1-5) days. Other signs observed were hepatomegaly 6(20.68), flapping tremors 3(10.34\%), ascites $3(10.34 \%)$ and splenomegaly 2 (6.89\%).

Mean serum bilirubin level was 14.3 \pm 9.0 (2.744.3) $\mathrm{mg} / \mathrm{dl}$, ALT was 1070 \pm 1249.95 (32-5972) U/L, PT was $38.6 \pm 30.65$ (15-120) secs and serum albumin $2.8 \pm 1.06(1.7-5.6) \mathrm{gm} / \mathrm{dl}$. Mean serum creatinine was $1.2 \pm 1.0(0.5-4.16) \mathrm{mg} / \mathrm{dl}$ and mean serum uric acid was $4.9 \pm 2.8 \mathrm{mg} / \mathrm{dl}(2-11.6) \mathrm{mg} /$ dl. IgM anti HAV was present in 1(3.44\%), HBsAg + IgM Anti HBc in 4(13.79\%) and IgM anti HEV in $22(75.86 \%)$ and no cause was found in 2 (6.89\%). Thirteen patients $(44.82 \%)$ had signs of raised intracranial pressure, 6\% (20.68) had bleeding and $7 \%$ (24.13) had renal failure. (Table I and II shows demographic, clinical and biochemical parameters of all patients).

Fourteen (48.27\%) patients were stable and discharged, 11\% (37.93) expired and $4 \%$ (13.79) left against medical advice. Only 7 (24.13\%) babies were born alive. (Table-III)

For comparison we divided our patients into three groups based on outcome of pregnancy: In $5(17.24 \%)$ cases pregnancy was terminated therapeutically after taking high risk consent from patients near relative. Thirteen (44.82\%) patients had a spontaneous expulsion of fetus and in 11 (37.93\%) patients pregnancy continued.

Demographic, clinical and biochemical features and maternal and fetal outcomes were compared in three groups (Table-IV and V).

\section{DISCUSSION}

Fulminant hepatic failure includes a spectrum of clinical features characterized by acute liver injury, severe hepatocellular dysfunction and hepatic encephalopathy. ${ }^{4}$ Hepatitis $E$ is the most common cause of fulminant hepatic failure in pregnancy. ${ }^{5,6}$ Pregnant women in developing countries are at an increased risk of acute hepatitis $E$ and its serious complications. ${ }^{6}$ Maternal mortality due to fulminant hepatitis $E$ is higher as compared to other causes of FHF. Both maternal and fetal complications can occur including abortion, premature labour, postpartum haemorrhage, maternal and fetal or 
neonatal death. ${ }^{7}$ Management is supportive and termination of pregnancy is not done routinely. ${ }^{8}$

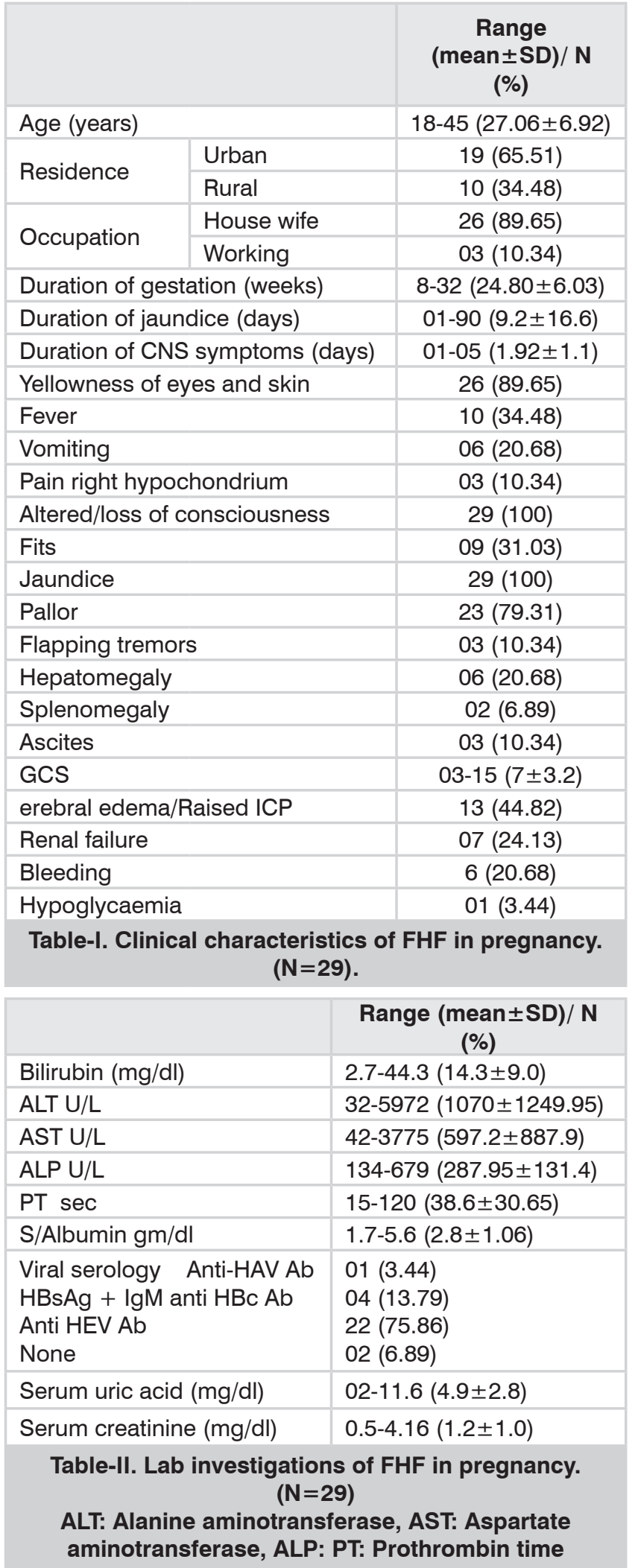

Professional Med J 2021;28(10):1501-1507.
In our study, the mean age of patients was $27.06 \pm 6.92$ years. Similarly mean age of patients observed by Brohi et al in Isra University Hospital Hyderabad was $29.04 \pm 8.404$ years and by Khuro et al was $28.74+5.76$ years $^{9,10}$ Desai observed a mean age of $24.8 \pm 0.6$ years. ${ }^{7}$ So patients in most of the studies were in third decade of life.

Our study demonstrated that $34.5 \%$ patient's belonged to rural areas as compared to $73.1 \%$ patients from rural areas in Brohi's study. ${ }^{9}$ This shows that in our country pregnant women in rural areas have limited access to a tertiary care hospital for their medical problems.

In our study mean duration of gestation at the time of presentation was $6.2 \pm 1.52$ months. Brohi observed that $80.7 \%$ patients presented in third trimester. $^{9}$

We observed that mean duration of jaundice at the time of presentation was $9.21 \pm 16.66$ days while Sahai observed a mean duration of $4.57 \pm 2.932$ days. ${ }^{11}$ It also shows that patients present late to tertiary care hospitals after onset of jaundice.

Mean duration of encephalopathy at presentation was $1.92 \pm 1.1$ days in our study while it was 20 hours as observed by Patra etal. ${ }^{12}$ This again shows late referral of our serious patients to tertiary care hospital.

Jaundice was present in $100 \%$ of our cases. Li also observed jaundice in $100 \%$ cases $^{3}$ while Sahai found it in only $58 \%$ patients. ${ }^{11}$

We found hepatitis $A$ in $3.4 \%$ cases while Sahai found it in $13.5 \%$ cases. ${ }^{11}$ This shows that hepatitis $A$ is uncommon in adults as $96 \%$ of our population is exposed to it before the age of 5 , so adults are immune. ${ }^{11}$

Hepatitis B was seen in $13.79 \%$ patients. Brohi observed hepatitis B in $17.3 \%$ cases and Sahai in $7.4 \%{ }^{9,11}$

We found HEV in $75.9 \%$ cases. Similarly Sahai observed hepatitis E in $77.9 \%$ cases. ${ }^{11}$ Brohi and Shuaib in Pakistan observed hepatitis E in 53. 


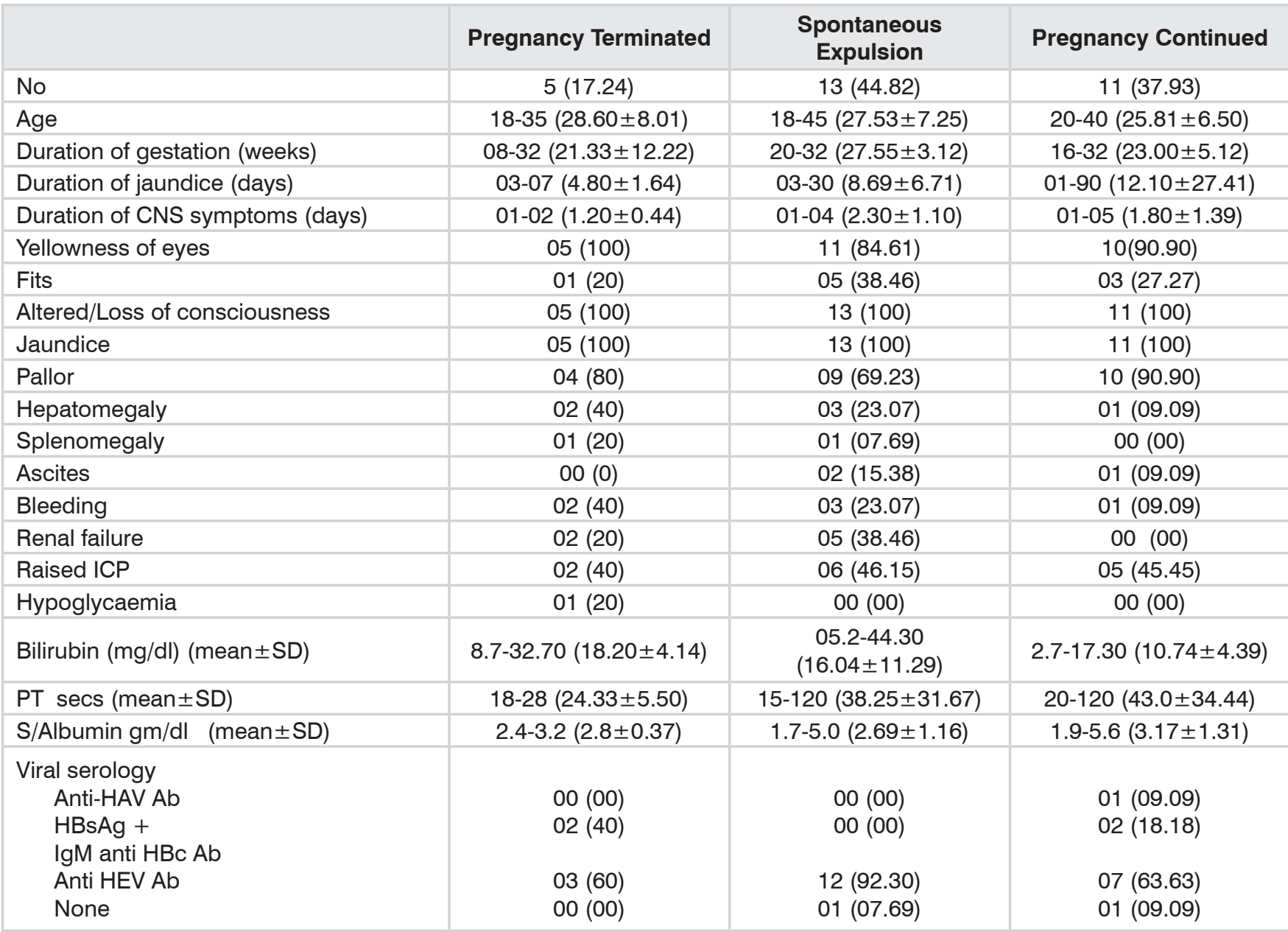

Table-IV. Comparison of three groups.

\begin{tabular}{|l|c|c|c|}
\hline & Pregnancy Terminated & Spontaneous Expulsion & Pregnancy Continued \\
\hline No & $5(17.24)$ & $13(44.82)$ & $11(37.93)$ \\
\hline Maternal outcome & & & \\
Discharged & $03(60)$ & $06(46.15)$ & $05(45.45)$ \\
Expired & $01(20)$ & $05(38.46)$ & $05(45.45)$ \\
LAMA/DOR & $01(20)$ & $02(15.38)$ & $01(09.09)$ \\
\hline Fetal mortality & $05(100)$ & $11(84.61)$ & $05(45.5)$ \\
\hline
\end{tabular}

Table-V. Maternal and fetal outcomes in 3 groups.

$8 \%$ and $58.9 \%$ cases respectively. ${ }^{9,13}$ Conversely, Khuroo found that $95.7 \%$ patients of FHF had HEV infection. ${ }^{10}$ As hepatitis $E$ spreads by feco-oral route so this indicates lack of good sanitation and clean drinking water in these countries. ${ }^{14}$ Beniwal also reported HEV as the most common etiology of $\mathrm{FHF}$ in pregnancy. ${ }^{15}$

We did not observe any case of hepatitis $C$ similar to Beniwal ${ }^{15}$ and Khuroo et al while Sahai observed acute hepatitis $\mathrm{C}$ in $1.5 \%$ cases. ${ }^{10,11}$ On the other hand, Brohi observed it in $13.5 \%$ cases. ${ }^{9}$ Hepatitis C was previously considered a rare cause of fulminant hepatic failure but now observed as an important cause in many studies. ${ }^{16,17}$

We did not find any case of acute fatty liver of pregnancy which is also an important cause of FHF in pregnancy. Sahai reported acute fatty liver of pregnancy in $3.57 \%$ cases. ${ }^{11}$ We could not find 
any etiology in $2 \%$ cases. The underlying cause might be AFLP which in the early phase is similar to viral hepatitis.

We found mean bilirubin of $14.3 \pm 9.0 \mathrm{mg} / \mathrm{dl}$ and Brohi observed mean bilirubin of $18.144 \pm 6.72$ $\mathrm{mg} / \mathrm{dl}$ indicating significant liver dysfunction. ${ }^{9}$ While Sahai found that mean Bilirubin was $8.52 \pm 6.11 \mathrm{mg} / \mathrm{dl}^{11}$

Mean PT (Prothrombin time) of our patients was $38.6 \pm 30.65$ seconds comparable with other studies (46.58 and 26.19 \pm 23.02 seconds in Brohi's and Sahai's patients respectively)..$^{9,11}$ Mean serum albumin of our patients was $2.8 \pm 1.06 \mathrm{gm} /$ dl similar to $2.8 \pm 0.445 \mathrm{gm} / \mathrm{dl}$ as observed by $\mathrm{Li}$ et $\mathrm{al}^{3}$ and close to $2.596 \pm 7.48 \mathrm{gm} / \mathrm{dl}$ as observed by Brohi. ${ }^{9}$ Prothrombin time and serum albumin are important prognostic markers of fulminant hepatic failure.

Most common complication observed in our patients was cerebral edema $(44.82 \%)$ while other complications observed were renal failure (24.13\%) and bleeding (20.68\%). Likewise Shinde observed Gl bleed in 25\% and renal failure in 21\% cases. ${ }^{7}$ However Brohi observed complications less frequently (cerebral edema in $3.8 \%$ cases, renal failure in $7.7 \%$ and $\mathrm{PPH}$ in $16.2 \%) .{ }^{9} \mathrm{We}$ observed complications more frequently in our patients stressing the need of intensive care.

We observed an overall mortality of $37.93 \%$ which is much higher than other studies. Brohi observed mortality rate of $28.8 \%$ and Sahai in $19.11 \% .^{9,11}$ This could be because of delay in access to medical facilities.

Fetal mortality in our study was $72.4 \%$, comparable with $77 \%$ in Brohi's study but much higher than that observed by Sahai (42.6\%). ${ }^{9,11}$

In $17.24 \%$ patients, pregnancy was terminated on therapeutic grounds to save the life of mother. $44.82 \%$ of our patients had spontaneous expulsion of fetus. $36.36 \%$ cases observed by Sahai et al had spontaneous delivery and it was more common in those patients who survived. ${ }^{11}$ In remaining patients $(37.93 \%)$ pregnancy continued and either the patient died or was discharged on request.

No significant difference was observed in clinical and biochemical parameters among the three groups. However it was observed that mortality rate $(20 \%)$ is much lower if pregnancy was terminated as compared to (45.5\%) when pregnancy was continued. Although bleeding occurred more frequently $(40 \%)$ in patients who underwent termination, it was managed successfully as confirmed by low mortality in this group. However Banait et al did not find any difference in maternal mortality in patients who delivered as compared to those who did not. ${ }^{18}$

To our knowledge few studies have been done to see maternal outcome in FHF and no such study has been done in our setup. Pregnant women with viral hepatitis have exaggerated immune response which triggers fulminant hepatic failure, so it should be logical to deliver the fetus as soon as possible to save the life of mother as is done in HELLP syndrome and acute fatty liver of pregnancy. ${ }^{19,20}$

It was a limited observational study with a small sample size. Another study with larger sample size can be done to prove it further.

\section{CONCLUSION}

Jaundice with altered level of consciousness is the most common presentation. Hepatitis $E$ is the most common cause of fulminant hepatic failure in pregnancy. Patients with FHF in pregnancy present late and maternal mortality rate is very high specially if pregnancy continues.

There is a dire need for provision of a clean and healthy environment to pregnant women as yet no vaccine is available against HEV in Pakistan. In order to reduce maternal and perinatal death rate in FHF, antenatal health services should be improved with early referrals to tertiary care hospitals. Liver transplant program in Pakistan should provide this facility in tertiary care hospitals in South Punjab. Early delivery should be attempted to save the life of mother.

Copyright $(15$ Mar, 2021. 


\section{REFERENCES}

1. Patra S, Kumar A, Trivedi SS, Puri M, Sarin SK. Maternal and fetal outcomes in pregnant women with acute Hepatitis E virus infection. Ann Intern Med. 2007; 147(1):28-33. doi:10.7326/0003-4819-1471-200707030-00005.

2. Pandey CK, Karna ST, Pandey VK, Tandon M. Acute liver failure in pregnancy: Challenges and management. Indian J Anaesth. 2015; 59(3):144-49. doi: 10.4103/0019-5049.153035.

3. Li XM, Ma L, Yang YB, Shi ZJ, Zhou SS. Clinical characteristics of fulminant hepatitis in pregnancy. World J Gastroenterol. 2005; 11(29):4600-3. doi: 10.3748/wjg.v11.i29.4600.

4. Paschoal FMJ, Nogueira RC, Oliveira ML, Paschoal EHA, Teixeira MJ, D'Albuquerque LAC, et al. Cerebral hemodynamic and metabolic changes in fulminant hepatic failure. Arq Neuropsiquiatr. 2017; 75(7):470-76. doi: 10.1590/0004-282X20170076.

5. Shalimar, Acharya SK. Hepatitis E and acute liver failure in pregnancy. J Clin Exp Hepatol. 2013 Sep; 3(3):213-24. doi: 10.1016/j.jceh.2013.08.009.

6. Karna R, Hazam RK, Borkakoti J, Kumar A, Kar P. A 5-year single-center experience of Hepatitis E Virus Infection during pregnancy. J Clin Exp Hepatol. 2020; 10(2):135-38. doi: 10.1016/j.jceh.2019.09.003.

7. Shinde NR, Patil TB, Deshpande AS, Gulhane RV, Patil $M B$, Bansod YV. Clinical profile, maternal and fetal outcomes of acute hepatitis $E$ in pregnancy. Ann Med Health Sci Res. 2014; 4(8):133-9. doi:104103/21419248.138033.

8. Desai A, Kansara V, Oza H, Ninama P, Paryani DJ. The prognosis of fulminant hepatic failure in pregnant women due to Hepatitis E. Euroasian J HepatoGastroenterol. 2013; 3(2):94-96.

9. Brohi ZP, Sadaf A, Perveen U. Etiology, clinical features and outcome of fulminant hepatic failure in pregnancy. J Pak Med Assoc. 2013; 63(9):1168-71. PMID: 24601199.

10. Khuroo MS, Kamili S. Aetiology, clinical course and outcome of sporadic acute viral hepatitis in pregnancy. $\mathrm{J}$ Viral Hepat. 2003; 10(1):61-9. doi: 10.1046/j.1365-2893.2003.00398.x.
11. Sahai $S$, Kiran R. Acute liver failure in pregnancy: Causative and prognostic factors. Saudi J Gastroenterol. 2015; 21(1):30-34. doi:10.4103/13193767.151221.

12. Patra S, Kumar A, Trivedi SS, Puri M, Sarin SK. Maternal and fetal outcomes in pregnant women with acute hepatitis E virus infection. Ann Intern Med. 2007; 147(1):28-33.

13. Shuaib $M$, Ashraf $R$, Imranullah $M$, Nadeem $M$. Hepatitis- $E$ induced fulminant hepatic failure in pregnancy and its associated mortality. JIMDC; 2015:4(3):96-98.

14. Navaneethan U, Al Mohajer M, Shata MT. Hepatitis E and pregnancy: Understanding the pathogenesis. Liver Int. 2008; 28(9):1190-99. doi: 10.1111/j-14783231.2008 . 01840.x.

15. Beniwal M, Kumar A, Kar P, Jilani N, Sharma JB. Prevalence and severity of acute viral hepatitis and fulminant hepatitis during pregnancy: A prospective study from North India. Indian J Med Microbiol. 2003; 21(3):184-5. PMID: 17643015.

16. Gordon FD, Anastopoulos H, Khettry U, Loda M, Jenkins RL, Lewis WD, et al. Hepatitis $\mathbf{C}$ infection: A rare cause of fulminant hepatic failure. Am J Gastroenterol. 1995; 90(1):117-20. PMID: 7801910.

17. Younis BB, Arshad R, Khurhsid S, Masood J, Nazir F, Tahira M. Fulminant hepatic failure (FHF) due to acute hepatitis C. Pak J Med Sci. 2015; 31(4):1009-11. doi: 10.12669/pjms.314.7618.

18. Banait VS, Sandur V, Parikh F, Murugesh M, Ranka P, Ramesh VS, et al. Outcome of acute liver failure due to acute hepatitis $\mathrm{E}$ in pregnant women. Indian $\mathrm{J}$ Gastroenterol. 2007; 26(1):6-10. PMID: 17401226.

19. Haram K, Svendsen E, Abildgaard U. The HELLP syndrome: Clinical issues and management. $A$ Review. BMC Pregnancy Childbirth. 2009; (26)9:8. doi: 10.1186/1471-2393-98. PMID: 19245695; PMCID: PMC2654858.

20. Liu J, Ghaziani TT, Wolf JL. Acute fatty liver disease of pregnancy: Updates in pathogenesis, diagnosis, and management. Am J Gastroenterol. 2017; 112(6):83846. doi: 10.1038/ajg.2017.54. 


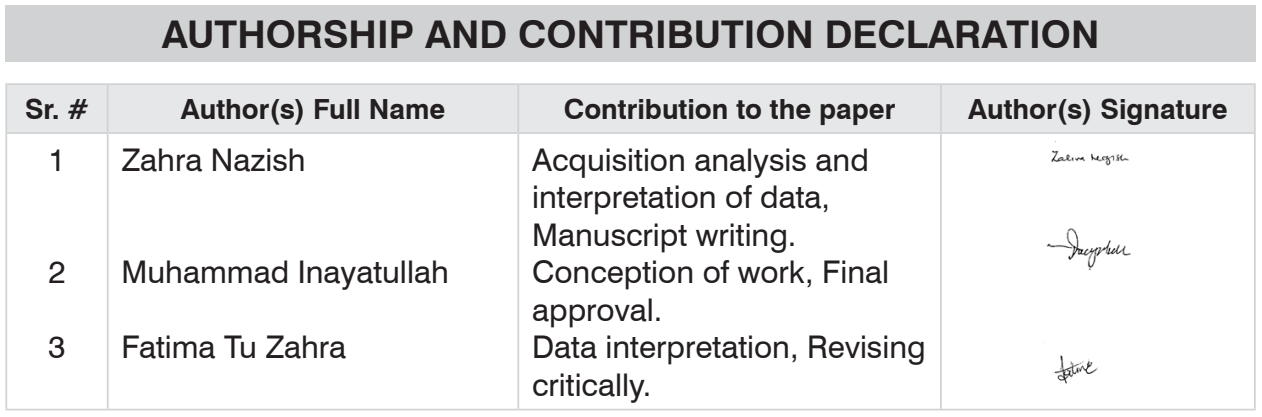

